This item was submitted to Loughborough's Research Repository by the author.

Items in Figshare are protected by copyright, with all rights reserved, unless otherwise indicated.

\title{
A two frame feedback linearization scheme for the control of fully rated wind generating units
}

\section{PLEASE CITE THE PUBLISHED VERSION}

https://doi.org/10.1109/PTC.2017.7981006

PUBLISHER

(C) IEEE

VERSION

AM (Accepted Manuscript)

LICENCE

CC BY-NC-ND 4.0

\section{REPOSITORY RECORD}

Bonfiglio, Andrea, Lorenzo Di Grigoli, Renato Procopio, Samir M. Alhejaj, and Francisco M. Gonzalez-Longatt. 2019. "A Two Frame Feedback Linearization Scheme for the Control of Fully Rated Wind Generating Units". figshare. https://hdl.handle.net/2134/25766. 


\section{A two frame Feedback Linearization scheme for the control of fully rated wind generating units}

\author{
A. Bonfiglio, L. Di Grigoli, R. Procopio, Member, IEEE \\ University of Genoa - DITEN, Department of ICT, Electrical \\ \& Naval Engineering \\ Via Opera Pia 11A, I-16143 Genova, ITALY \\ a.bonfiglio@unige.it
}

\author{
S.M. Alhejaj, F. Gonzalez-Longatt, Senior Member, IEEE \\ The Wolfson School: Electronic, Electrical and System \\ Engineering \\ Loughborough University, Loughborough UK \\ F.Gonzalez-Longatt@lboro.ac.uk
}

\begin{abstract}
The present paper proposes an innovative control scheme for a fully rated wind generating unit equipped with a permanent magnet synchronous generator. The main objective of this control strategy is that of allowing a decoupled and dynamically performing control of active power (by the MPPT curve) and reactive power at the point of interconnection to the grid. Moreover, the control will be able to integrate frequency supporting logics, such as synthetic inertial control and active power curtailment. The control synthesis is fully detailed and validated by means of dedicated simulations in comparison with the traditional control scheme for this type of wind generators.
\end{abstract}

Index Terms - Wind generation, non-linear control techniques, Feedback Linearization, power systems modelling, distributed energy resources.

\section{INTRODUCTION}

The aim of the present paper is to propose an innovative control architecture for a fully rated Wind Turbine Generator (WTG )equipped with a Permanent Magnet Synchronous Generator (PMSG) based on the Feedback Linearization (FBL) technique. In recent years, there has been an intense increasing of applications of model based control technique in the field of power systems [1, 2]. Among all these techniques, the FBL allows providing an algebraic linearization of the nonlinear system and, for MIMO processes, the decoupling of the dynamics of the regulated channels [3]. Thanks to this procedure, it is very simple to design a control system whose closed loop dynamics can be defined via a pole placement and provide the tracking of the reference signal [3]. The FBL technique has been widely employed in robotics and electronics [4], but its application is also becoming more and more relevant in the electricity power systems [5-7]. The proposed approach will focus on a two-frame linearization of the system accounting separately for the design of the Machine Side Converter (MSC) control and the Grid Side Converter (GSC) one. This "separation" of the system dynamics is allowed by the availability of electrical measurements at the DC link that is the only way of interaction between the two subsystems. This will lead to the definition of two simpler structures to design the converter controllers, avoiding the necessity to account for a unique non-linear dynamical system to be linearized. The aim of the proposed strategy is to provide a performing and decoupled control of the WTG that will allow pursuing the maximum power production of the generator with the minimum machine stator current and providing regulation of the reactive power injection keeping constant the DC link voltage. Moreover, the system is designed to be capable of accounting for the integration of frequency support and active power curtailment logics in compliance with the current technical regulations and grid connection requirements of various countries [8-10]. In the following, the system modelling of a WTG equipped with a PMSG is fully detailed then, the FBL control design is going to be detailed and its performances are going to be tested against a traditional, PID based, controller.

\section{WIND GENERATING UNIT MODEL}

In this section, the overall model of the WTG is proposed. Fig. 1 depicts the one line diagram of the WTG.

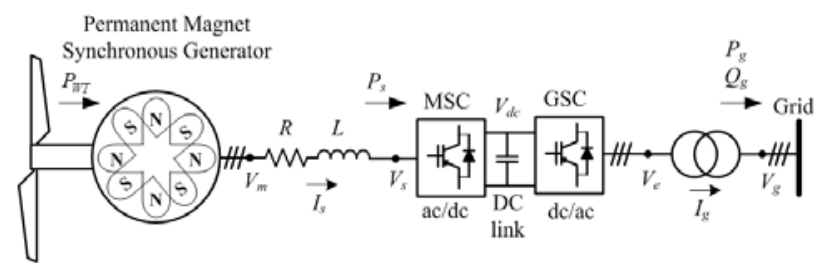

Figure 1. Wind turbine layout.

The WTG can be seen as a sixth order dynamic non-linear system characterized by four controlled inputs (two per converter) and four controlled quantities (namely reactive power at the grid side, the DC link voltage, the generator stator current direct axis component and the generator stator current quadrature axis component). The idea of the proposed control is that of defining two dynamic nonlinear sub-systems, one for the GSC and the other for the MSC to provide a simplified synthesis of the FBL controller.

\section{A. Machine Side Converter model}

The MSC will control the PMSG active power to achieve the maximum power from the wind and minimizing the amplitude of the machine stator current (performing the control of the current direct axis component). The Maximum Power Point Tracking (MPPT) is achieved defining an optimal speed for the wind generator by the optimal power vs. rotors speed 
curve [11]. The MSC sub-system considers the model of the interaction between the wind and the turbine rotor, the PMSG dynamics and, of course, the converter itself. The torque provided by the WTG rotor $\left(T_{w}\right)$ is related to the rotor model, which accounts for the power form the wind and the blades performances [12]:

$$
\begin{aligned}
& T_{w}\left(\omega_{r}, v_{w}, \beta\right)=\frac{\rho A}{2 S_{b} \omega_{r}} c_{p}(\lambda, \beta) v_{w}^{3} \\
& \left\{\begin{array}{l}
\lambda=\frac{R_{b} \omega_{r}}{v_{w}} \\
c_{p}=0.22\left(\frac{116}{\lambda_{i}}-0.4 \beta-5\right) e^{-\frac{12.5}{\lambda_{i}}} \\
\lambda_{i}=\frac{1}{\lambda+0.08 \beta}-\frac{0.035}{\beta^{3}+1}
\end{array}\right.
\end{aligned}
$$

where $S_{b}$ is the WTG rated power (W), $\rho$ is the air density $\left(\mathrm{kg} / \mathrm{m}^{3}\right) ; A$ is the area covered by the rotor $\left(\mathrm{m}^{2}\right), \beta$ is the pitch angle of rotor blades (deg), $v_{w}$ is the wind speed at hub height upstream the rotor $(\mathrm{m} / \mathrm{s})$ and $\omega_{r}$ is the turbine angular speed in p.u. on the base of the rated machine speed $\omega_{r n}, c_{p}$ is the performance coefficient, $\lambda$ is the tip speed ratio and $R_{b}$ is the rotor radius $(\mathrm{m})$. The motion equation of the rotor can be expressed as:

$$
\frac{P_{W T}}{\omega_{r}}-T_{e}=2 H \frac{d \omega_{r}}{d t}
$$

being $T_{e}$ the torque provided by the generator and $H$ the rotor inertia expressed in s.

The application of Kirchhoff voltage law at the mesh composed by the PMSG, an R-L cable connection and the MSC lead to the following set of dynamic equations in the Park domain on a rotor oriented frame (in p.u. on $S_{b}$ base):

$$
\left\{\begin{array}{l}
v_{s d}=-\left(R_{s}+R\right) i_{s d}-\frac{L+L_{d}}{\omega_{n}} \frac{d i_{s d}}{d t}-\omega_{r}\left(L+L_{q}\right) i_{s q} \\
v_{s q}=-\left(R_{s}+R\right) i_{s q}-\frac{L+L_{q}}{\omega_{n}} \frac{d i_{s q}}{d t}+\omega_{r}\left(L+L_{d}\right) i_{s d}+\omega_{r} \psi
\end{array}\right.
$$

Being $v_{s d(q)}$ the direc (quadrature) axis components of the voltage at the AC side of the MSC, $R_{s}$ is the stator resistance, $R$ is the cable resistance, $L$ is the cable inductance, $i_{s d(q)}$ is the direct (quadrature) axis component of the PMSG stator current, $L_{d(q)}$ is the direct (quadrature) axis reactance of the machine, $\omega_{n}$ is the system rated angular speed and $\psi$ is the generator permanent magnet flux. Moreover, the PMSG torque can be written as:

$$
T_{e}=-i_{s d} \phi_{s q}+i_{s q} \phi_{s d}=\left(L_{d}-L_{q}\right) i_{s d} i_{s q}+\psi i_{s q}
$$

More details about the WTG model can be found in [13]. After some simple algebraic manipulations of Eq.s (3)-(5), the MSC system can be expressed as:

$$
\left\{\begin{array}{l}
\frac{d i_{s d}}{d t}=-\frac{\omega_{n}}{L_{d T}}\left(R_{T} i_{s d}+L_{q T} i_{s q} \omega_{r}+v_{s d}\right) \\
\frac{d i_{s d}}{d t}=-\frac{\omega_{n}}{L_{q T}}\left(R_{T} i_{s q}-L_{d T} i_{s d} \omega_{r}-\omega_{r} \psi+v_{s q}\right) \\
\frac{d \omega_{r}}{d t}=\frac{1}{2 H}\left(T_{w}\left(\omega_{r}, \beta\right)-\left(L_{d}-L_{q}\right) i_{s d} i_{s q}-\psi i_{s q}\right)
\end{array}\right.
$$

where the system state components are the direct and quadrature axis components of the stator current, $i_{s d}$ and $i_{s q}$, and the WTG rotor speed, $\omega_{r}$ (from now on $x_{1}, x_{2}$ and $x_{3}$ ). The inputs of the first sub-system are the direct and quadrature component of the MSC AC voltage, $v_{s q}$ and $v_{s d}$ (from now on $u_{1}$ and $u_{2}$ ) and $R_{T}$ and $X_{d(q) T}$ are the total resistance and direct (quadrature) axis reactance at the machine side defined as:

$$
\left\{\begin{array}{l}
R_{T}=R+R_{s} \\
L_{d(q) T}=L+L_{d(q)}
\end{array}\right.
$$

The first sub-system can be written in the normal form $\dot{x}=f(x)+g(x) \cdot u$ where:

$$
f_{1}(x)=\left[\begin{array}{c}
-\frac{\omega_{n}}{L_{d T}}\left(R_{T} x_{1}+L_{q T} x_{2} x_{3}\right) \\
-\frac{\omega_{n}}{L_{q T}}\left(R_{T} x_{2}+L_{d T} x_{1} x_{3}-x_{3} \psi\right) \\
\frac{1}{2 H}\left(T_{w}\left(x_{3}, \beta\right)+\left(L_{d}-L_{q}\right) x_{1} x_{2}-\psi x_{2}\right)
\end{array}\right]
$$

The controlled outputs can be expressed as function of the sub-system state variables as:

$$
\left\{\begin{array}{l}
h_{1}(x)=x_{1} \\
h_{2}(x)=x_{2}
\end{array} .\right.
$$

\section{B. Grid Side Converter model}

The GSC is interfaced with the WTG by means of the DC link which provides a decoupling between the two systems. As a result, the GSC system can be seen as an independent system which deals with the machine side via the DC link voltage dynamic equation. The DC side of the GSC is connected to the DC link where a capacitance is installed in order to support the DC voltage. The dynamics of the voltage on the DC link is driven by the current balance between the machine side and the grid side, i.e.:

$$
C \frac{d V_{D C}}{d t}=\frac{P_{M S C}-P_{G S C}}{V_{D C}}
$$

being $P_{G S C}$ the power delivered at the AC sides of the GSC, $P_{M S C}$ the power coming from the WTG at the AC side 
terminals of the MSC and C is the DC link capacitance. Then, it necessary to consider the Kirchhoff voltage law of the mesh consisting on the GSC, an R-L connection and the main grid. In a generic Park reference frame, it is possible writing the following axis equations:

$$
\left\{\begin{array}{l}
v_{g d}=v_{e d}-R_{T} i_{g d}-\frac{L_{T}}{\omega_{n}} \frac{d}{d t} i_{g d}-\omega_{e} L_{T} i_{g q} \\
v_{g q}=v_{e q}-R_{T} i_{g q}-\frac{L_{T}}{\omega_{n}} \frac{d}{d t} i_{g q}+\omega_{e} L_{T} i_{g d}
\end{array}\right.
$$

Where $v_{g d(q)}$ and $v_{e d(q)}$ are respectively the direct (quadrature) axis components of the grid and GSC voltages, $\dot{i}_{g d(q)}$ is the direct (quadrature) axis components of the grid side current, $\omega_{e}$ is the p.u. frequency of the grid and $L_{T}$ and $R_{T}$ are the parameters of the connections between the GSC and the main grid. The Park reference for the grid side converter is assumed synchronized with the grid voltage, so that the voltage $V_{e}$ has only direct axis component and the active and reactive power delivered to the grid can be written as:

$$
\left\{\begin{array}{l}
P_{g}=v_{g d} i_{g d} \\
Q_{g}=v_{g d} i_{g q}
\end{array}\right.
$$

This implies that it is possible to control the active power acting on $i_{g d}$ and controlling the reactive one acting on the only $i_{g q}$. After some algebraic manipulations of (11) and (12) it is possible to define the following third order system for the GSC:

$$
\left\{\begin{array}{l}
\frac{d i_{g d}}{d t}=\frac{\omega_{n}}{L_{T}}\left(-v_{g d}-R_{T} i_{g d}-\omega_{e} L_{T} i_{s q}+\frac{\sqrt{3}}{2 \sqrt{2}} V_{D C} u_{g d}\right) \\
\frac{d i_{g q}}{d t}=\frac{\omega_{n}}{L_{T}}\left(-v_{g q}-R_{T} i_{g q}+\omega_{e} L_{T} i_{s d}+\frac{\sqrt{3}}{2 \sqrt{2}} V_{D C} u_{g q}\right) \\
\frac{d V_{D C}}{d t}=\frac{1}{C V_{D C}}\left(P_{M S C}\left(x_{1}, x_{2}, x_{3}\right)-\frac{\sqrt{3}}{2 \sqrt{2}} V_{D C}\left(u_{g d} i_{g d}+u_{g q} i_{g q}\right)\right)
\end{array}\right.
$$

Being $u_{g d}$ and $u_{g q}$ the axis components of the modulation signals of the inverter, highlighted to account for the dependency on the DC link voltage. The inputs of the GSC are, from now on defined as $u_{3}$ and $u_{4}$. The GSC state components are the direct and quadrature axis components of the grid current, $i_{g d}$ and $i_{g q}$, and the DC link voltage, $V_{D C}$ (from now on $x_{4}, x_{5}$ and $x_{6}$ ). The second sub-system can be written in the normal form as:

$$
f_{2}(x)=\left[\begin{array}{c}
\frac{\omega_{n}}{L_{T}}\left(-v_{g d}-R_{T} x_{4}-\omega_{e} L_{T} x_{5}\right) \\
\frac{\omega_{n}}{L_{T}}\left(-v_{g q}-R_{T} x_{5}+\omega_{e} L_{T} x_{4}\right) \\
\frac{P_{M S C}\left(x_{1}, x_{2}, x_{3}\right)}{C x_{6}}
\end{array}\right]
$$

$$
g_{2}(x) \cdot u=\left[\begin{array}{c}
\frac{\sqrt{3}}{2 \sqrt{2}} \frac{\omega_{n}}{L_{T}} x_{6} u_{3} \\
\frac{\sqrt{3}}{2 \sqrt{2}} \frac{\omega_{n}}{L_{T}} x_{6} u_{4} \\
\frac{\sqrt{3}}{2 \sqrt{2} C}\left(x_{4} u_{3}+x_{5} u_{4}\right)
\end{array}\right] .
$$

As one can notice, the element that produces the coupling of the two dynamic sub-systems is described by the active power from the MSC at the DC link. This quantity can be easily measured with an accurate dynamic thus allowing considering system (14) as an independent third order dynamic system. Since the aim of the control of the GSC is that of keeping constant the voltage at the DC link, and controlling the reactive power provided to the grid, the controlled outputs can be expressed as functions of the sub-system state variables as:

$$
\left\{\begin{array}{l}
h_{3}(x)=x_{5} \\
h_{4}(x)=x_{6}
\end{array} .\right.
$$

\section{FEEDBACK LINEARIZATION}

The objective of the FBL is that of defining two fictitious inputs for every sub-system (four in total) which will define a linear and decoupled system with the design system outputs. This will result in a state transformation of the system where the new states of the system are going to be the controlled system outputs and, eventually, their time derivatives. It is worth noticing that the states of the two sub-systems are measurable, resulting in an actual applicability of the FBL procedure and state transformation avoiding the application of estimators that may limit the effectiveness of the proposed approach.

\section{A. Machine side converter linearization}

If one considers the MSC, it is possible to apply the FBL procedure performing the time derivatives of each of the two outputs until one of the two inputs explicitly appears. With some algebraic manipulation, it is possible to obtain that, after a first order derivative of $h_{1}(x)$, input one appears while, after a first order derivative of $h_{2}(x)$, input two appears. The two fictitious inputs of the linearized system $\left(v_{1}\right.$ and $\left.v_{2}\right)$ are then defined as:

$$
\left\{\begin{array}{c}
v_{1}=\dot{h}_{1}(x)=-\frac{\omega_{n}}{L_{d T}}\left(R_{T} x_{1}+L_{q T} x_{2} x_{3}+u_{1}\right) \\
v_{2}=\dot{h}_{2}(x)=-\frac{\omega_{n}}{L_{q T}}\left(R_{T} x_{2}-L_{d T} x_{1} x_{3}-\psi x_{3}+u_{2}\right)
\end{array}\right.
$$

The schematic representation of the FBL structure for the MSC is depicted in Fig. 2. 


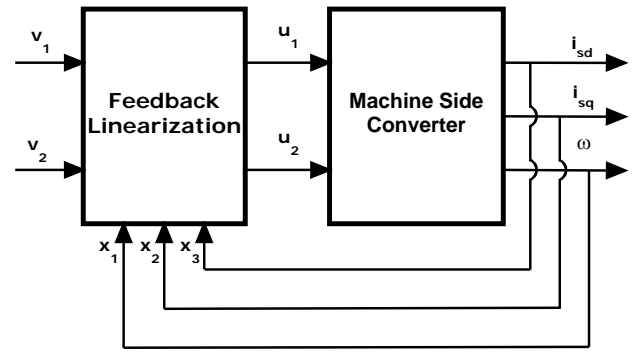

Figure 2. MSC linearization scheme.

The content of the FBL control block will be given by the inversion of system (18):

$$
\left\{\begin{array}{c}
u_{1}=\frac{L_{d T}}{\omega_{n}} v_{1}+R_{T} x_{1}+L_{q T} x_{2} x_{3} \\
u_{2}=\frac{L_{q T}}{\omega_{n}} v_{2}+R_{T} x_{2}-L_{d T} x_{1} x_{3}-\psi x_{3}
\end{array} .\right.
$$

The obtained relation between the new fictitious inputs and the controlled outputs is linear and decoupled, as shown in Fig. 3.

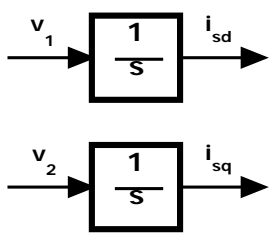

Figure 3. Equivalent linear relations of the transformed system.

\section{B. Grid side converter linearization}

The FBL theory is now applied to the GSC following the same procedure used for the machine side one. The aim of the GSC converter is that of controlling the quadrature axis current (proportional to the reactive power) and the voltage at the DC link. Performing the time derivatives of these two quantities, it is possible noticing that, after a first order derivative of $h_{3}(x)$, input three appears while, after a first order derivative of $h_{4}(x)$, input four appears. The two fictitious inputs of the linearized GSC system $\left(v_{3}\right.$ and $\left.v_{4}\right)$ are then defined as:

$$
\left\{\begin{array}{l}
v_{3}=\dot{h}_{3}(x)=\frac{\omega_{n}}{L_{T}}\left(\frac{\sqrt{3}}{2 \sqrt{2}} x_{6} u_{4}-v_{g q}-R_{T} x_{5}+\omega_{e} L_{T} x_{4}\right) \\
v_{4}=\dot{h}_{4}(x)=\frac{P_{M S C}}{x_{6} C}-\frac{\sqrt{3}}{2 \sqrt{2} C}\left(x_{4} u_{3}+x_{5} u_{4}\right)
\end{array}\right.
$$

For both the controllers, the relative degree of the linearized system, the sum of the maximum derivative order of every controlled output, is equal to two. Since the order of each subsystem is three, there exists an internal dynamics in the linearized system that has to be stable, otherwise compromising the stability of the whole system. As one can see in [14], it is possible to show that the linearization of PWM inverter is stable, according to the FBL theory. Once that the FBL technique has been successfully applied, it is necessary to define the structure of the regulating channels of the system. Following the design criteria provided in [3] it is possible to implement the following regulator structure:

$$
v_{2}=K_{\text {isq }}\left(i_{s q, r e f}-i_{s q}\right)
$$

Recalling the second of (18) it is possible to describe the dynamic of the closed loop system with the following Cauchy problem:

$$
\left\{\begin{array}{l}
\frac{d i_{s q}}{d t}+K_{i s q} i_{s q}=K_{i s q} i_{s q, r e f} \\
i_{s q}(0)=i_{s q 0}
\end{array}\right.
$$

In this condition, the roots that describes the dynamic of the system are represented by the solutions of:

$$
\lambda_{\text {isq }}+K_{\text {isq }}=0
$$

It is clear from (23) that this structure allows placing the poles of the system and so defining the dynamic behavior of the system time response. For the sake of brevity, details are provided for the only quadrature axis current since they can be extended identically to the other three regulating channels. The proposed structure of control accounts for the following reference signals: $i_{s d, r e f}, i_{s q, r e f}, V_{D C, \text { ref }}$ and $i_{g d, \text { ref }}$. The direct quadrature axis component is normally kept to zero in order to minimize the overall system losses and the DC link voltage is set to 1 p.u. on the DC link rated voltage base. The quadrature axis component of the stator current is obtained on the basis of the reference power coming from the WTG Maximum Power Point Tracking (MPPT). This characteristic is given as a function of the rotor angular speed and can be expressed as [13]:

$$
P_{\text {ref }}=\frac{\rho A R_{b} C_{p, o p t}}{2 S_{b} \lambda_{\text {opt }}} \omega_{r}^{3}
$$

This structure can be easily used to implement a limitation signal from the transmission system operator, using a minimum selection between the MPPT reference and the power limitation signal, or integrated with additional frequency support signal coming from a kinetic energy controller by simple summing with MPPT reference. In accordance to (5), under the hypothesis of (7), the reference of the quadrature axis component of the stator current can be calculated as:

$$
i_{s q, r e f}=\frac{P_{r e f}}{\psi \omega_{r}}
$$

On the other hand, $i_{g d, r e f}$ can be calculated on the basis of the reactive power reference $Q_{g \text {,ref }}$ using the second of (13):

$$
i_{g q, r e f}=\frac{Q_{g, r e f}}{v_{g d}}
$$

The FBL controller is also integrated with the pitch control system, that has the aim of keeping the rotor at a maximum admissible speed for wind speed higher that the rated one. The working principle of such controller is the following: when the electric machine angular speed exceeds a specified threshold (e.g. 1.2 p.u.), the controller changes the value of the pitch angle in order to reduce the power extracted from the wind. Since the pitch control works only for over synchronous speeds, an anti-wind up limiter locks the pitch angle to 0 for sub synchronous speeds (Fig. 4). 


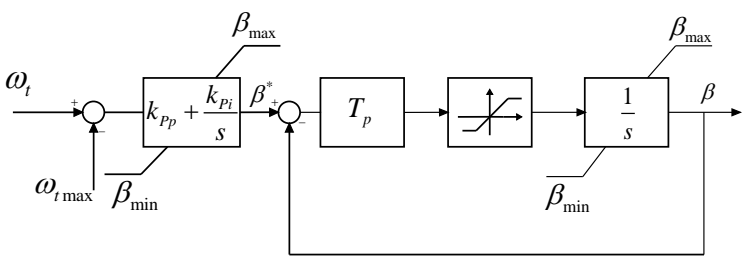

Figure 4. Pitch angle controller block scheme

The overall control scheme proposed is reported in Fig. 5.

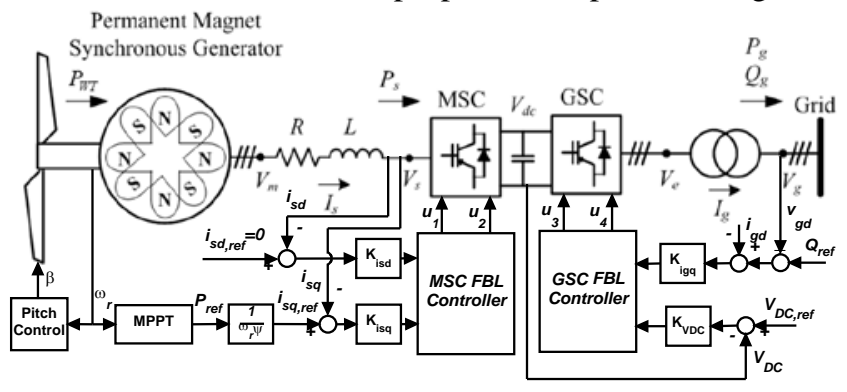

Figure 5. Overall scheme of the proposed FBL controller.

IV. SIMULATIONS AND RESUltS

In order to validate the proposed control strategy a set of simulations has been set up to provide a comparison against a traditional, PID based, controller. The traditional control loop accounts for internal control loops (two for each converter) to regulate the direct and quadrature axis current. The current references are provided by external loops realized by Proportional-Integral (PI) controllers. The MSC is equipped with the same MPPT reference proposed for the FBL controller. The power reference is then provided to the to a power regulator that provides the reference signal for the stator quadrature current component. The other control provides a zero reference to the stator direct quadrature current component. The GSC is equipped with two loops providing reactive power and DC link voltage control acting on the direct and quadrature components of the PWM modulation of the GSC. Both the controllers are also provided with a pitch regulating system in order to provide a speed limitation after a certain wind speed threshold, corresponding to the rated power production of the WTG. More details about the WTG traditional control scheme can be found in [13]. The comparison of the two controllers is performed considering a wind speed variation and reactive power reference variation. For the first case, the system is initialized into a condition corresponding to $7.5 \mathrm{~m} / \mathrm{s}$ wind speed. After $10 \mathrm{~s}$, a wind speed variation is provided, up to a value equal to $8.5 \mathrm{~m} / \mathrm{s}$. Another wind speed increasing is provided at $300 \mathrm{~s}$ to a wind speed equal to $16 \mathrm{~m} / \mathrm{s}$, corresponding to a condition where the pitch controller is activated. For the discussion of the results of the wind variation, the attention is mainly focused on the MSC (except for the evaluation of the active power delivered to the grid). As one can see from Fig. 6, the steady state values of the power delivered to the grid is correctly the same for the two control strategies since the MPPT curve is the same. However, the FBL controller presents a better dynamics, characterized by a less overshooting profile and a quicker time response. The same behavior can be observed in Fig. 7, reporting the quadrature axis stator current profile. Fig. 8 also highlights the better dynamic profile of the WTG rotor speed whose profile is almost non-oscillatory. The second part of the rotor speed transient is the same for both the controller since it is mainly affected by the pitch controller (that is the same for the two configurations). However, this transient highlights the good integration of the proposed control with the proper regulation system of the WTG.

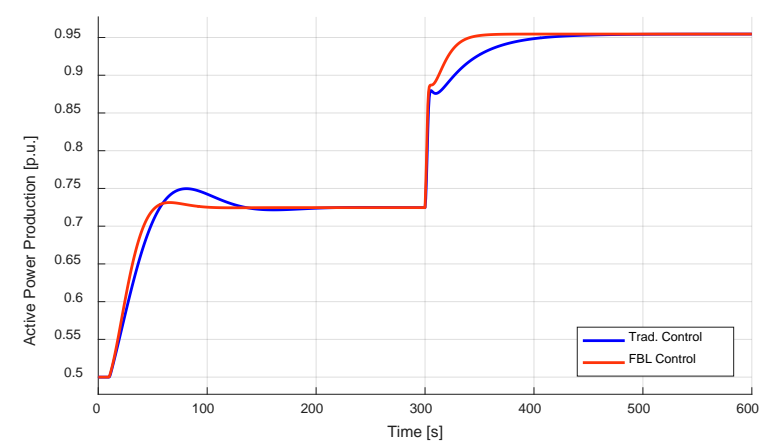

Figure 6. Active power production at the grid side time profile.

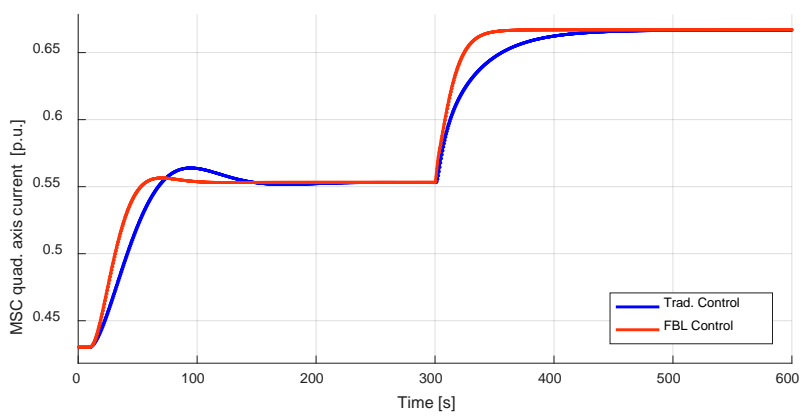

Figure 7. MSC stator current quadrature axis time profile.

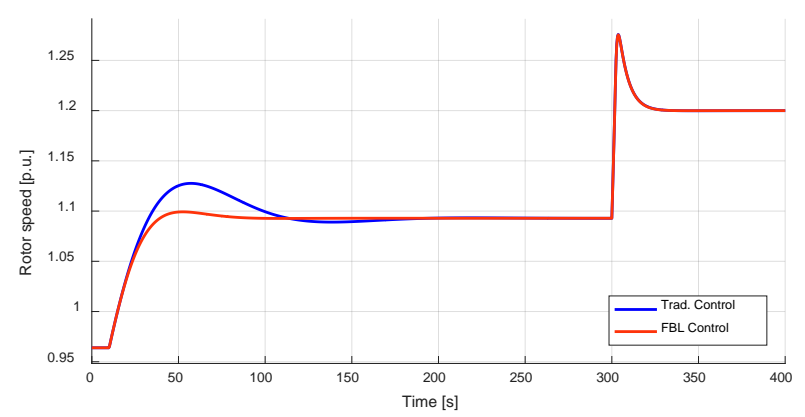

Figure 8. Rotor speed time profile.

Another effect of the FBL controller is the perfect decoupling of the DC link voltage (Fig. 9) while the same profile for the traditional regulation scheme is characterized by spikes and transient at every wind power variation. The second aspect considered is a reactive power reference of the GSC; the simulation accounts for an initial reactive power delivery to the grid equal to 0 p.u. before a first reactive power reference variation to 0.5 p.u. at $5 \mathrm{~s}$ and a following reduction to -0.5 p.u. at $10 \mathrm{~s}$. As for the first simulation case, for the reactive power variation only the GSC relevant quantities are shown. As one can see from Fig. 10, the performances of the two regulators are very similar. As a consequence of the reactive power variation, also the active power has a transient 
dynamics, due to the variation of the losses in the resistance of the connection between the GSC and the grid (Fig. 11). Also in this configuration, the DC link voltage is kept constant during all the transient with the FBL controller while for the traditional one there is a small dynamic started by the imbalance of the currents at the DC link side (Fig. 12).

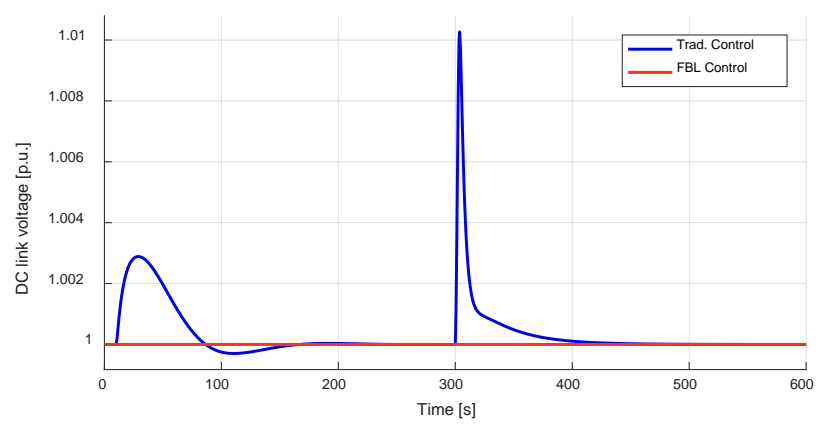

Figure 9. DC link voltage time profile.

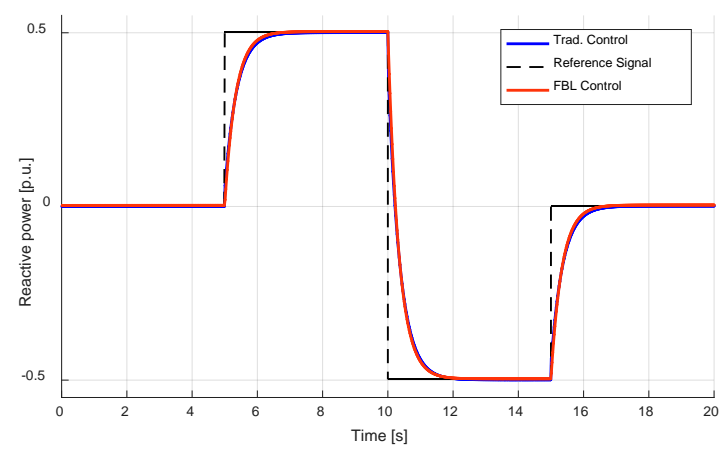

Figure 10. Reactive power time profile.

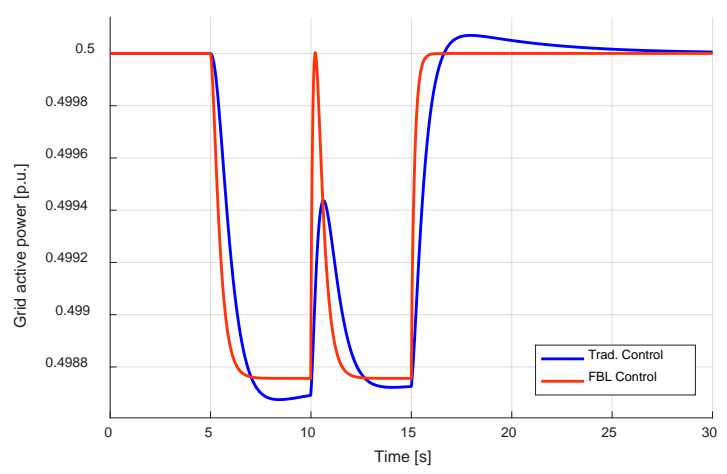

Figure 11. Reactive power time profile.

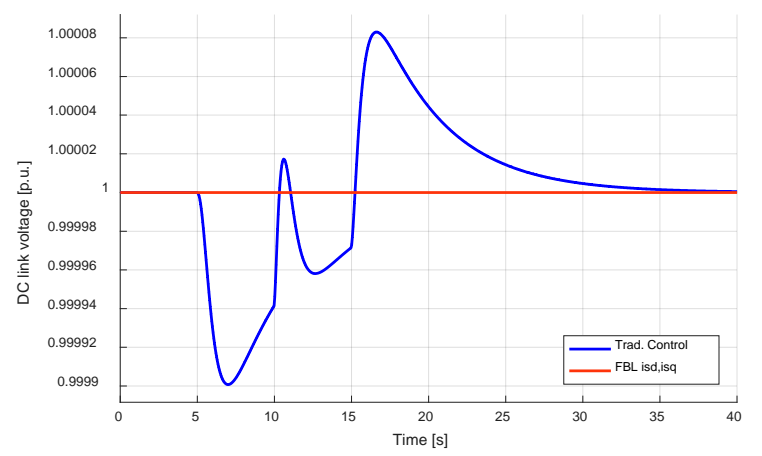

Figure 12. Reactive power time profile.

\section{CONCLUSIONS}

The aim of the present study was to define an innovative control strategy for a wind generating unit equipped with a PMSG using a FBL based approach. The paper proposed a modeling of the WTG that allowed separating the dynamics of the MSC from the one of the GSC by means of power measurement at the DC link. Under this hypothesis, it was possible to design two distinct regulators using the theory of the FBL in order to control the WTG in accordance to the MPPT and allowing reactive power regulation. The proposed control strategy has been tested against a traditional, PID based controller, for a WTG generator highlighting the potentials of the FBL approach. Future developments of the proposed research are related to the possibility of designing a frequency support logics providing a kinetic energy reserve to be implemented together with the FBL controller.

\section{REFERENCES}

[1] A. Bonfiglio, A. Oliveri, R. Procopio, F. Delfino, G. B. Denegri, M. Invernizzi, et al., "Improving power grids transient stability via Model Predictive Control," in Proceedings - 2014 Power Systems Computation Conference, PSCC 2014, 2014.

[2] K. Dahech, M. Allouche, T. Damak, and F. Tadeo, "Backstepping sliding mode control for maximum power point tracking of a photovoltaic system," Electric Power Systems Research, vol. 143, pp. 182-188, 2// 2017.

[3] J. J. E. Slotine and W. Li, Applied nonlinear control. Englewood Cliffs, N.J.: Prentice Hall, 1991.

[4] P. KyuCheol, C. Hakyoung, and L. Jang Gyu, "Point stabilization of mobile robots via state space exact feedback linearization," in Robotics and Automation, 1999. Proceedings. 1999 IEEE International Conference on, 1999, pp. 2626-2631 vol.4.

[5] J. Matas, L. G. d. Vicuna, J. Miret, J. M. Guerrero, and M. Castilla, "Feedback Linearization of a Single-Phase Active Power Filter via Sliding Mode Control," IEEE Transactions on Power Electronics, vol. 23, pp. 116-125, 2008.

[6] A. Bonfiglio, S. Cacciacarne, M. Invernizzi, R. Procopio, S. Schiano, and I. Torre, "Gas turbine generating units control via feedback linearization approach," Energy, vol. 121, pp. 491-512, 2017.

[7] A. Bonfiglio, F. Delfino, M. Invernizzi, A. Perfumo, and R. Procopio, "A feedback linearization scheme for the control of synchronous generators," Electric Power Components and Systems, vol. 40, pp. 18421869, 2012.

[8] C. Norm, "CEI 0-16: Regola tecnica di riferimento per la connessione di Utenti attivi e passivi alle reti AT ed MT delle imprese distributrici di energia elettrica," Comitato Elettrotecnico Italiano, Mailand, 2012.

[9] E.-E. N. Code, "Requirements for Grid Connection Applicable to all Generators," European Network of Transmission System Operators for Electricity, ENTSO-E (2013 March), 2013.

[10]A. Bonfiglio, F. Delfino, M. Invernizzi, R. Procopio, and P. Serra, "Criteria for the equivalent modeling of large photovoltaic power plants," in IEEE Power and Energy Society General Meeting, 2014.

[11]J. G. Slootweg, "Representing distributed resources in power system dynamics simulations," in Power Engineering Society Summer Meeting, 2002 IEEE, 2002, pp. 176-178 vol.1.

[12]F. Milano, Power system modelling and scripting: Springer Science \& Business Media, 2010.

[13] A. Bonfiglio, F. Delfino, M. Invernizzi, and R. Procopio, "Modeling and Maximum Power Point Tracking Control of Wind Generating Units Equipped with Permanent Magnet Synchronous Generators in Presence of Losses," Energies, vol. 10, p. 102, 2017.

[14]F. Delfino, G. B. Denegri, M. Invernizzi, and R. Procopio, "Feedback linearisation oriented approach to $\mathrm{Q}-\mathrm{V}$ control of grid connected photovoltaic units," IET Renewable Power Generation, vol. 6, pp. 324339, 2012. 